\title{
Influence of Water Binder Ratio on High Performance Concrete
}

\author{
N. Seshadri Sekhar ${ }^{1, *}$ and P.N. Raghunath ${ }^{2}$ \\ ${ }^{I}$ Department of Civil and Structural Engineering, Annamalai University, Chidambaram, India; ${ }^{2}$ Annamalai University, \\ Chidambaram, Tamilnadu, India
}

\begin{abstract}
High performance concrete M60 cubes of $150 \mathrm{~mm}$ X $150 \mathrm{~mm}$ X $150 \mathrm{~mm}$ were tested experimentally under static loading. With the variation in the water binder ratios of $0.25,0.28,0.33,0.39$ and hyper plasticizer of $0.6 \% .0 .8 \%$. $1.0 \%, 1.2 \%$ the cubes were cast and accordingly the cylinders were cast. For each ratio of water binder, 12 cubes and 2 cylinders were cast. Out of 12 cubes, 3 cubes were cured for 7 days, 3cubes for 15 days, 3 cubes for 21 days and the balance 3 cubes for 28 days. All the cubes were tested in a $2000 \mathrm{kn}$ compression testing machine. The load deflection curves, stress- strain curves were drawn for each cube and cylinder. The average compressive strength of each mix for different number of days of curing were calculated. The modulus of elasticity was calculated for each design mix.
\end{abstract}

Keywords: Water binder ratio, HPC concrete, compressive strength.

\section{INTRODUCTION}

Concrete is widely being used in all types of structures as a main component. When people started the long span structure like infrastructures, skyscrapers, marine structures in the midst of ocean, the high strength and high performance concretes were invented by adding pozzolanic materials and admixtures for partial replacement or addition to cement and for low water cement ratios. In the recent times, the high performance concrete of more than M30 is being used in all types of structures. By reducing the water cement ratio and increasing the percentage of plasticizer the compressive strength of the concrete increases for the same mix ratios. The increase of the admixtures like silica fume or fly ash or zeolite or blast furnace slag increases the compressive strength of the concrete. But after reaching a point of saturation the strength decreases rapidly.

The HPC is prepared with ordinary Portland cement of 53 grade complying to IS: 12269 , [1] and using zeolite, fly ash, silica fume as admixtures and as partial replacement to cement to the extent of $5 \%, 10 \%, 15 \%$ and $30 \%$ with w/c ratio 0.27 to 0.45 along with coarse aggregate and fine aggregate and super plasticizer, the 28 day characteristic strength being achieved ranging from 103.8 $\mathrm{MPa}$ to 114.7 $\mathrm{MPa}$ [2]. By using both ultra-fine fly ash and silica fume as replacement of $15 \%$ of cement along with use of $0.5 \%$ of super plasticizer by weight of cement better characteristic strength achieved than that of ultra-fine fly ash HPC and silica fume HPC. The authors have analyzed the pore structure, and micro hardness to compare the compressive strength and flexural strength of all the concretes [3]. The optimum proportions of concrete mixes are achieved by considering the cost of the material with respect to different countries. The authors have discussed as when and where to

*Address correspondence to this author at the Annamalai University, Chidambaram, Tamilnadu, India; Tel: +919443282646;

Emails: seshadrinsekhar@yahoo.com and seshadrinsekhar@gmail.com use high performance concrete by considering the factors such as shrinkage, curing, super plasticizer with cement. It was proposed that there are specific proportions for getting the required cylinder strengths for some countries [4]. HPC was designed through the minimum void ratio method, by replacing the cement with slag and silica fumes partially and $15 \%$ of sand by fly ash. Stress curves for compressive, splitting and flexural strengths of HPC specimens were measured and indicated that the experimental concretes had better pastes to void ratios than control batches ratio. $\mathrm{N}=$ $\mathrm{Vp} / \mathrm{Vv}=1.3$ Where $\mathrm{Vp}=$ Paste volume and $\mathrm{Vv}=$ Voids volume. The results indicated that pozzolanic material not only provided chemical strength effect, but also provided physical packing effect. The compressive stress curves may keep growing as the concrete ages [5]. High performance concretes with 56-day compressive strengths of $65 \mathrm{MPa}$ to $75 \mathrm{MPa}$ (with silica fume) and $95 \mathrm{MPa}, 105 \mathrm{MPa}$ and $120 \mathrm{MPa}$ (without silica fume) under high sustained compressive strengths were studied. It was observed that the long-term sustained compressive strength of HPC under small eccentric loads is approximately 5\% higher than under concentric loads. A modification of ACI $318 \mathrm{M}$ equation for the modulus of elasticity of weight high performance normal concrete was recommended [6].

The paper presents the results of experimental investigations carried out on varied water binder ratios with varied percentages of hyper plasticizer and number of days of curing. The paper also discusses the behavior of the cubes as well as their ultimate capacity under static loading. The deflection, and energy absorbed were studied with every increase in loading. Conclusions drawn on investigations are also presented.

\section{EXPERIMENTAL PROGRAMME}

The mix proportion of concrete was obtained by trial and error method and designed as per the IS code 10262-2009 with the proportions per cubic meter of it. The different percentages of hyper plasticizer were used to compensate the 
lesser water binder ratio. The typical quantities of materials used for the concrete mix with w/b ratio of 0.33 i.e., Cement: Fine Aggregate: Coarse Aggregates: Silica Fume = $1: 1.73: 2.51: 0.055$ and the percentage of hyper plasticizer is shown in (Table 1).

Table 1. Properties and Quantities of Materials Used Typical to $\mathbf{w} / \mathrm{b}$ Ratio of $\mathbf{0 . 3 3}$

\begin{tabular}{|l|l|l|}
\hline \multicolumn{1}{|c|}{ Details } & \multicolumn{1}{|c|}{ Content } & \multicolumn{1}{|c|}{$\begin{array}{l}\text { Specific } \\
\text { Gravity }\end{array}$} \\
\hline \hline Targeted 28 day concrete strength & $60 \mathrm{MPa}$ & \\
Cement- 53 grade-IS.22269 & $450 \mathrm{Kg}$ & 3.15 \\
Max. size of coarse aggregate & $20 \mathrm{~mm}$ & 2.74 \\
Weight of 20 mm aggregate & $680 \mathrm{~kg}$ & 2.74 \\
Min. size of aggregate & $10 \mathrm{~mm}$ & 2.54 \\
Weight of 10 mm aggregate & $450 \mathrm{~kg}$ & 0.600 \\
Fine aggregate & $780 \mathrm{~kg}$ & 1.00 \\
Silica Fume(S.F) & $25 \mathrm{~kg}$ & \\
Hyperplastisizer-Gilinum233(BASF) & $380 \mathrm{gr}$ & \\
=[0.8\% (cement +SF)] & $166.25 \mathrm{Kg}$ & \\
Water & & \\
\hline
\end{tabular}

Forty eight cubes having a size $150 \mathrm{~mm} \mathrm{X} 150 \mathrm{~mm} \mathrm{X}$ $150 \mathrm{~mm}$ were cast 12 for each water binder ratio. Table 2 shows the description of the cubes. With each water cement ratio three specimens were cured for 7 days, three for 14 days, three for 21 days and three for 28 days for each water binder ratio. All the cubes are tested under $2000 \mathrm{kn}$ compressive testing machine. The deflections were noted with respect to unit increase in loading. The ultimate compressive strength of the cubes was noted. The failure patterns were recorded. Load deflection curves were drawn for all the cubes. The strain energy absorbed for all increased loads were calculated. The cumulative energy absorbed was calculated. It was found that the strain energy absorbed was greater in 28 days cured cubes and lesser in water cement ratio cubes.

For each water binder ratio two cylinders were cast and cured for 28 days with wet gunny bags. The cylinders were tested for finding the elastic modulus of the concrete. With the recorded deflections the strains were calculated and with each increased loading the stresses induced were calculated. The stress- strain curves were drawn and calculated the elastic modulus of the concrete analytically. It was found that the elastic modulus was more in lesser water binder ratio cylinders.

\section{TESTING}

The compression tests were conducted in compression testing machine $2000 \mathrm{Kn}$ capacity of Heico brand. The top and bottom of the cubes were made plain by filling the small pores with lime powder. $3 \mathrm{~mm}$ thick plywood sheet was kept on top and bottom of the cube. After placing the cubes horizontally on the bottom jaw, by using the adjustable buttons the top jaw was moved to fix the cube firmly. Load was applied on the cube with an increase of $25 \mathrm{KN}$. For each load increase, the deflections readings were noted. The deflections were noted with the help of mechanical dial gauge. At ultimate load the deflections were noted. The first crack load, first crack width, and first crack length were measured. Load - deflection curve was drawn. The area under the curve gives the dissipated energy which is given in (Table 3). A typical load-deflection curve for 7 days cured and 28 days cured cubes and cylinder of 28 days curing are given separately in (Fig. 1).

Fig. (2) shows the Typical Stress- Strain diagram for $\mathrm{w} / \mathrm{b}=0.33,7$ days curing and 28 days curing of cubes and cylinder with 28 days curing.

The strength of the cubes for an initial period of 7 days curing, 14 days curing, 21 days curing and 28 days curing were noted. The strength of different cubes with varied water binder ratios was noted.

The area covered by the load deflection curve gives the strain energy absorbed by the cube or cylinder. From the graph of Stress-Strain, the elastic modulus of the concrete is achieved.

The comparative study of the different cubes with varied days of curing is given in (Fig. 3).

\section{RESULTS AND DISCUSSIONS}

The following observations were made:

1. The load V/s deflection curves follow the same pattern for all types of cubes i.e. for 7 days of curing, 14 days of curing, 21 days of curing and 28days of curing. The area under the curve of 7days cured cube is much less than the area under the curve of 28 days cured cubes. It shows that the total energy absorbed is less in case of 7 days cured cubes. This pattern is observed in 14 days cured cubes and 21 days cured cubes. It is also observed that in 28 days cured cube, the initial deflection is zero up to $600 \mathrm{Kn}$ of static loading. This shows curing plays a major role in initial deflection and strength.

2. Stress v/s strain curve also follows the same pattern for 7 days, 14 days, 21 days and 28 days of curing. It is also observed that in 28 days cured cube, the initial strain is zero upto $600 \mathrm{Kn}$ of static loading. This shows that curing plays a major role in initial stain and strength.

Table 2. Details of the Cubes

\begin{tabular}{|c|c|c|c|c|c|c|c|}
\hline S. No & $\begin{array}{c}\text { Cubes } \\
\text { Designation }\end{array}$ & $\begin{array}{l}\text { No. of } \\
\text { Cubes }\end{array}$ & $\begin{array}{c}\text { Water Cement } \\
\text { Ratio }\end{array}$ & $\begin{array}{c}\text { Water Binder } \\
\text { ratio }\end{array}$ & $\begin{array}{c}\text { Percentage } \\
\text { Quantity of Hyper } \\
\text { plasticizer }\end{array}$ & $\begin{array}{l}\text { Average Slump } \\
\text { in } \mathbf{~ m m}\end{array}$ & $\begin{array}{c}28 \text { day Ultimate } \\
\text { Compressive Strength in } \\
\text { kn/sq.mm }\end{array}$ \\
\hline $\begin{array}{l}1 \\
2 \\
3 \\
4\end{array}$ & $\begin{array}{l}\text { A28 } \\
\text { B28 } \\
\text { C28 } \\
\text { D28 }\end{array}$ & $\begin{array}{l}3 \text { no. } \\
3 \text { no. } \\
3 \text { no. } \\
3 \text { no. }\end{array}$ & $\begin{array}{l}0.27 \\
0.30 \\
0.35 \\
0.42\end{array}$ & $\begin{array}{l}0.25 \\
0.28 \\
0.33 \\
0.39\end{array}$ & $\begin{array}{l}1.2 \\
1.0 \\
0.8 \\
0.6\end{array}$ & $\begin{array}{l}272 \mathrm{~mm} \\
270 \mathrm{~mm} \\
269 \mathrm{~mm} \\
228 \mathrm{~mm}\end{array}$ & $\begin{array}{l}71.11111 \\
64.00000 \\
60.58 \\
64.88888\end{array}$ \\
\hline
\end{tabular}



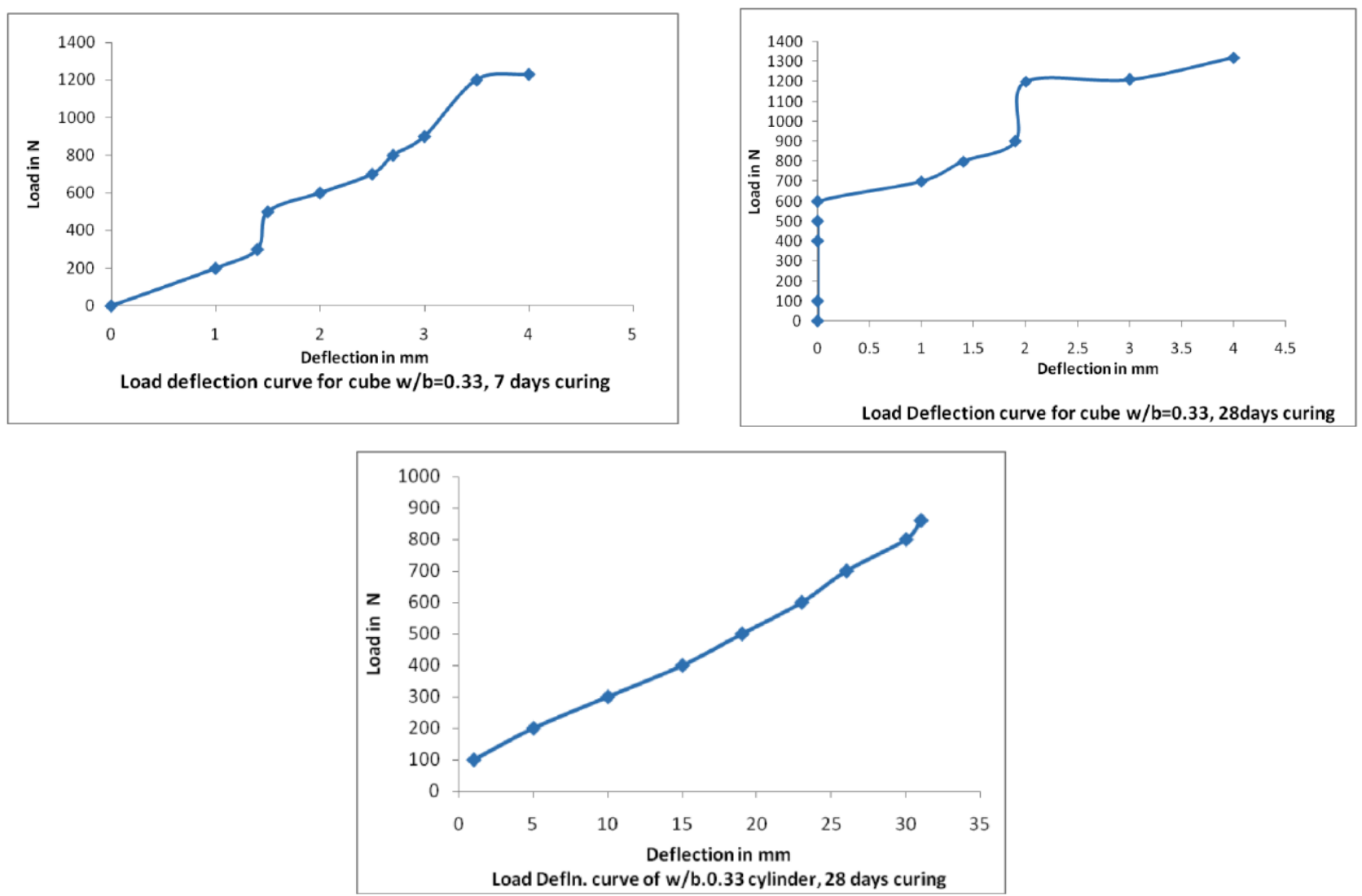

Fig. (1). Typical Load Deflection curves for $w / b=0.33$ of Cubes and cylinder.
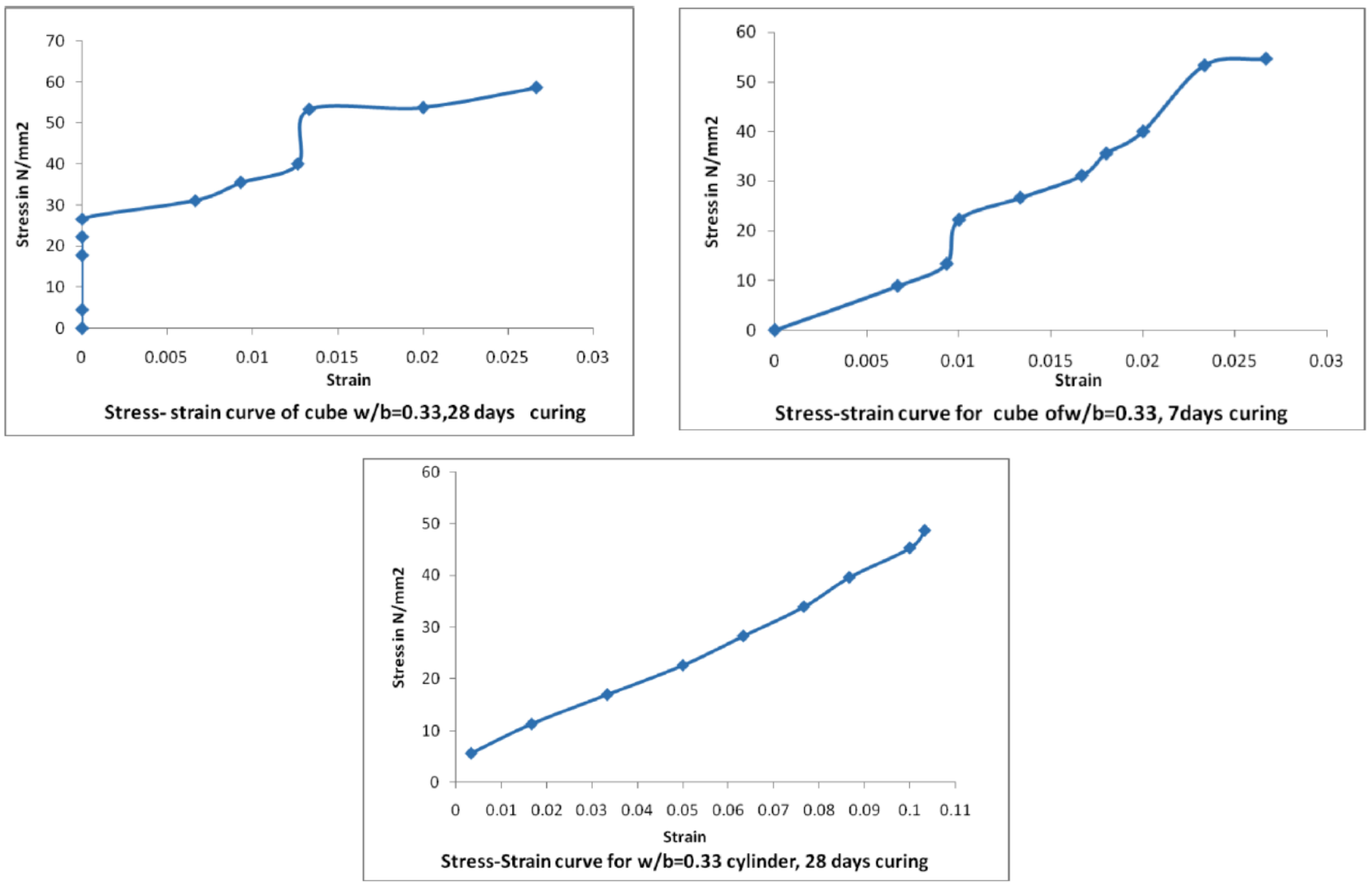

Fig. (2). Typical Stress-Strain curves for $\mathrm{w} / \mathrm{b}=0.33$ cubes and cylinder. 
3. In case of cylinders, the Load-Deflection curve and Stress- Strain curve are observed to be almost linear, as compared with other cylinders like W/B ratio of 0.25 , $0.28,0.33$ and 0.39 . The stress strain curve of cylinders gives the Young's Modulus of the concrete. It is observed from the elastic modulus curve that the water binder ratio is a constraint to be considered for achieving the required Young's modulus of the concrete.

4. Fig. (3) Compression strength shows the growth of compression strength with number of days of curing. It also shows the variation of compression strength with factors like water binder ratio.

Table 3. Properties of Concrete with $w / b=0.33$

\begin{tabular}{|c|c|c|}
\hline S.No & Property & Results in MPa \\
\hline \hline 1. & Cube compressive strength & 60.58 \\
2. & Cylinder compressive strength (Average) & 41.27 \\
3. & Young's Modulus & $2.25 \times 10^{4}$ \\
4. & Slump & $270 \mathrm{~mm}$ \\
\hline
\end{tabular}

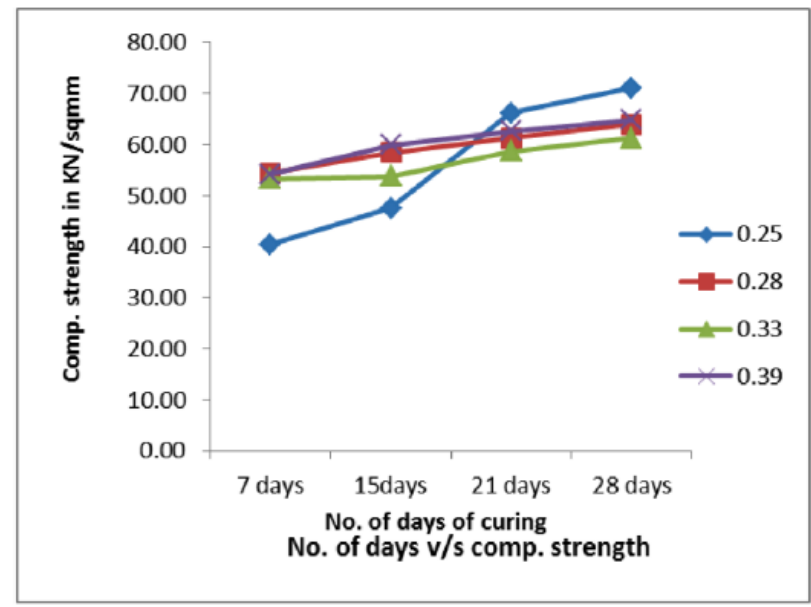

Fig. (3). No. of days of curing-Compressive strength.

\section{CONCLUSIONS}

In this investigation, the behavior of cubes was studied and the ultimate capacity was evaluated. The failure patterns of cubes were established. The load-deflection curve shows the less percentage of ultimate loading and lesser percentage of energy absorption in 7 days curing cubes whereas in the case of 28 days cured cubes the energy absorbed will be maximum. The percentage of hyper plasticizer also affects the strength of the cubes. Moreover, the water binder ratio affects the strength of the cube. The cylindrical strength concrete also shows the same way as in cubes. Fig. (3) shows the typical behavior of the concretes. The optimum percentage of $w / b=0.33$ as there is substantial growth in initial strength and the difference between initial strength and final strength is very less. But otherwise the cubes of $\mathrm{w} / \mathrm{b}$ ratio beginning with initial strength are substantially less.

\section{CONFLICT OF INTEREST}

The author(s) confirm that this article content has no conflicts of interest.

\section{ACKNOWLEDGEMENT}

My sincere thanks to Prof. Dr. Thandavamoorthy T.S., Former Deputy Director, Structural Engineering Research Centre, and Professor, Department of Civil Engineering, Adhiparasakthi Engineering College, Melmaruvathur who shared his knowledge on fatigue loading which provided clear picture about the project and for his continuous help in guiding the first writer.

\section{REFERENCES}

[1] Indian standard code specification for 53 grade Ordinary Portland Cement 12269-1997.

[2] Y.N. Sammy, and J. Xihuang, "High performance concrete incorporating zeolite, fly ash, and silica fume", SP172-50, American Concrete Institute, December 1, pp. 951-970, 1999.

[3] S. Wei, P. Ganghua, and D. Dajun, "Effect of combined use of ultra fine fly ash and silica fume on strength of HPC", SP172-16, American Concrete Institute, pp. 299-312 .

[4] A. Neville, and P.C. Aitcin, "High performance concrete-An overview," Materials and Structures, vol. 31, pp. 111-117, 1998.

[5] P.K. Chang, "Stress curves and mechanical properties of high performance concrete", Journal of the Chinese Institute of Engineers, vol. 27, no.7, pp.1081-1085, 2004.

[6] S. Iravani, and J.G. Macgregor, "High Performance concrete under high sustained compressive stresses", Structural Engineering report, Department of Civil Engineering, University of Alberta, June 1994.

Received: August 18, 2013

Revised: December 07, 2013

Accepted: December 09, 2013

(C) Sekhar and Raghunath; Licensee Bentham Open.

This is an open access article licensed under the terms of the Creative Commons Attribution Non-Commercial License (http://creativecommons.org/licenses/by-nc/3.0/) which permits unrestricted, non-commercial use, distribution and reproduction in any medium, provided the work is properly cited. 